\title{
Expression of Recombinant Fusion Protein of NDV from Escherichia coli BL-21 C-1b Clone using Accurapid ${ }^{\mathrm{TM}}$ Cell-Free Protein Expression System
}

\author{
Krisna Noli Andrian ${ }^{1}$ and Aris Haryanto ${ }^{1 *}$ \\ Universitas Gadjah Mada, Yogyakarta, Indonesia. \\ arisharyantodugm.ac.id
}

\begin{abstract}
Newcastle Disease (ND) is an infectious disease that infected poultry caused by Newcastle Disease Virus (NDV). NDV is a virus from family Paramyxoviridae which enveloped, unsegmented single strand (ss) RNA negative sense. Fusion (F) protein is an NDV protein that has an important role in the infection process of NDV to the host cell. F protein of NDV can induce the immune response of the host so that it has the potential to become an NDV vaccine. Recombinant plasmid pBT7-N-His-F has been designed by inserting the F protein-encoding gene of NDV. The inserted gene is an F protein of NDV from a local isolate from Galur, Kulon Progo, Yogyakarta. This study aimed to investigate the in vitro expression of the recombinant $\mathrm{F}$ of NDV from recombinant plasmid pBT7N-His-F NDV from E. coli BL-21 clone C-1b. Samples of recombinant plasmid pBT7N-His-F NDV showed a DNA fragment in size of $4.642 \mathrm{bp}$. The DNA fragment was then digested by the EcoRI enzyme to separate the pBT7-N-His vector with the F proteinencoding gene as a DNA insert. Restriction digest generated two DNA fragments in the size of $4.001 \mathrm{bp}$ and $642 \mathrm{bp}$. The in vitro expression of recombinant $\mathrm{F}$ protein was conducted using the AccuRapid ${ }^{\mathrm{TM}}$ Cell-free Expression system. The visualization of the expressed recombinant $\mathrm{F}$ protein using the SDS-PAGE method showed a recombinant protein fragment in size of $25.6 \mathrm{kDa}$. The Western blotting on the polyvinyl difluoride (PVDF) membrane showed a recombinant protein fragment in size of $25.6 \mathrm{kDa}$. The recombinant $\mathrm{F}$ protein of NDV was successfully in vitro expressed from clone $\mathrm{C}-1 \mathrm{~b}$ of recombinant plasmid pBT7-N-His-FNDV by AccuRapid ${ }^{\mathrm{TM}}$ Cell-free protein expression system.
\end{abstract}




\section{Introduction}

Newcastle Disease (ND) is a deadly disease with a high mortality rate that infecting both domestic (chickens, turkeys, pigeons, geese, ducks) as well as wild birds as the main target of its spread. Newcastle disease is caused by ND virus as its causative agent. This virus belongs to the genus Avulavirus, family Paramyxoviridae, order Mononegavirales. The ND virus is an enveloped virus with a diameter of 150 to $250 \mathrm{~nm}$ and has a nucleocapsid with a diameter of 15 to $18 \mathrm{~nm}$ with a spheric and helix symmetric shape of capsid. The ND virus has a single-stranded and negative-sense RNA, with a genome length of $15.2 \mathrm{~kb}$. The ND Virus has six genes of the protein encoders include Nucleoprotein $(N)$, Phosphoprotein $(P)$, Matrix protein $(M)$, Fusion protein $(F)$, Hemagglutinin-Neuraminidase (HN), and Polymerase protein (L) (Quinn et.al, 2011; Yamamoto et al., 2016).

Newcastle Disease is one of the most harmful diseases for its high distribution rate and morbidity which is ranged from $80 \%$ to $100 \%$ and mortality reaches $100 \%$ in unvaccinated poultry. Unfortunately, animals that have been vaccinated still had $60 \%$ of morbidity rates with mortality rates ranged from $6 \%$ to $50 \%$. Losses due to ND virus infections in Indonesia reached 142 billion rupiah per year due to their high mortality rates, decreased meat and egg production, and high cost in ND control (Czegeldi et al., 2006; Rehmani et al., 2015). ND virus also causes many types of infections with different pathogenicity. The type of infection is determined by the clinical symptoms in the infected animal, namely velogenic viscerotropic, velogenic neurotropic, mesogenic, lentogenic or respiratoric, and asymptomatic. The ND virus has receptors on the digestive and respiratory systems so that their target infection is in the gastrointestinal tract and respiratory of the animal. Velogenic pathotype infection has a high mortality rate whereas the mesogenic pathotype has a moderate mortality rate (Quinn et al., 2011; Lee et al., 2016).

ND virus is transmitted rapidly through direct contact with contaminated cage, feces, aerosols, excretion, and infected animal secretions. The spread of the ND virus can be controlled by vaccination so that the antibodies are formed to the ND virus to reduce the risk of its transmission to other healthy animals. Until now, the vaccination has proved to decrease the amount of ND transmission in poultry for both life attenuated vaccine and killed vaccine. A vaccine is performed better when derived from local isolates because it has the proximity of a genome with a circulating virus, however, the administration of vaccines did not fully succeed to provide immunity to the ND virus infection (Quinn et al., 2011; OIE, 2012).

Recombinant vaccines are one of the ND vaccines used for the induction of the host immune system. Recombinant vaccines have such advantages in preventing the return of the toxic properties of an antigen, beneficial to be used in expressing the desired genome, and preventing the co-purification from the unwanted contaminants. The ND virus Protein F recombinant is proven to induce chicken antibodies with a level that is almost the same as the commercial inactivated vaccine in Indonesia. Protein $\mathrm{F}$ recombinant expression resulted from plasmids pBT7-N-His-F with an F protein-encoding gene insertion from ND virus and injected into the chicken can become an ND virus recombinant vaccine (Nascimento and Leite, 2012; Astuti et al., 2018). The protein expression using AccuRapid ${ }^{\mathrm{TM}}$ Cell-free Protein Expression is a fast method and has great results for the process of in vitro protein expression. The expression of the ND virus Protein F recombinant using the AccuRapid ${ }^{\mathrm{TM}}$ Cell-free Protein Expression is carried out by inserting the F protein-encoding gene into the plasmid of pBT7-N-His. The plasmid pBT7-N-His-F is expressed in vitro resulting in a recombinant of F protein that has the potential to become an ND vaccine in Indonesia (Astuti et al., 2018). This research was aimed to investigate the in vitro protein expression of the Protein F recombinant of NDV which was inserted in the plasmid pBT7-N-His-F from E. coli BL-21 clone C-1b. 


\section{Materials and Methods}

\subsection{Sample}

The samples used in this study were recombinant plasmids pBT7-N-His-F from the bacterial colony of $E$. coli BL21 (BE3) clone of C-1b. Plasmids inserted by recombinant F protein-encoding of ND virus gene isolated from Galur, Kulon Progo (0663/04/2013).

\subsection{Materials}

In this study, we used several materials i.e. pBT7-N-His-F plasmids with protein F-encoding gene inserts from NDV, agarose (Genetika Science, Indonesia), acrylamide (MP Biomedical, USA), bisacrylamide (MP Biomedical, USA), EcoR1 (Thermo Fisher Scientific, USA), AccuRapid ${ }^{\mathrm{TM}}$ Cell-free Protein Expression Kit (Bioneer, South Korea), Tris-Borat-EDTA (TBE) (Biobasic, Canada), SYBR® Safe (Invitrogen, USA), DNA Ladder 100 bp (Thermo Fisher Scientific, USA), Glycerin Bromophenol Blue (GBB) (Biorad, Germany), Aquadest, Butanol (Merck, Germany), glacial acetic acid (MERCK, Germany), Coomassie Brilliant Blue (Sigma, USA), Ammonium persulfate (APS), Tetra Methylene Diamine (TEMED), Tris-HCl (Biobasic, Canada), Sodium Dodecyl Sulphate (SDS) (Merck, Germany), Glycine (Merck, Germany), Polyvinyl Difluoride (PVDF), Whatman paper, Methanol (Merck, Germany), Bovine Serum Albumin (BSA) blocker (Thermo Fisher Scientific, USA), Tween20® (Sigma-Aldrich, USA), Tris-Buffered Saline (TBS), Mouse 6x His epitope antibody Tag ( Invitrogen, USA), Goat Anti-Mouse IgG (Invitrogen, USA), 1-StepTM NBT/BCIP (Nitro-Blue tetrazolium chloride and 5-Bromo-4 Chloro 3' Indolylphospate P-Toluidine salt) (Thermo Fisher Scientific), Eppendorf tube (Axygen, USA), blue tip, yellow tip, white tip, and parafilm.

This research used a variety of tools as research support i.e. DNA Electrophoresis run view electromagnetic system device CS-300 V (Cleaver, United Kingdom), Thermo Shaker Waterbath NTS3000 (Eyela, Japan), Ultra Violet CMW-20, protein electrophoresis device Mini Protein II Cell (BioRad, USA), Blotter (H. Hoeltzel Blotter), Thermolyne Roto-Mix shaker type 50800, spin down centrifuge, digital balance PB303 (Mettler Toledo, USA), vortex mixer (Maxi Mix), Microwave, and micropipette series sized 1-10 $\mu \mathrm{L}, 10-100 \mu \mathrm{L}$, and 100-1000 $\mu \mathrm{L}$ (Thermo Fisher Scientific, USA), beaker glass (Pyrex, Germany), Erlenmeyer tubes (Pyrex, Germany), and reaction tubes (Pyrex, Germany).

\subsection{Methods}

DNA Electrophoresis of Recombinant Plasmid. Plasmid pBT7-N-His-F was visualized using $1 \%$ agarose gel electrophoresis. The agarose gel was made by mixing agarose powder $0.5 \mathrm{~g}$ in $50 \mathrm{ml}$ of TBE $1 \mathrm{x}$ in the Erlenmeyer tube and then heated in the microwave for 60 seconds. The mixture was awaited until dissolved and added $3 \mathrm{ml} \mathrm{SYBR®} \mathrm{Safe} \mathrm{and} \mathrm{mixed} \mathrm{until} \mathrm{homogeneous.} \mathrm{The} \mathrm{mixture} \mathrm{was}$ then poured into the agarose gel mold for electrophoresis until the gel was compacted. The compacted agarose gel was inserted into the electrophoresis device. Next, the Gel is soaked in TBE 1x as a buffer solution in the electrophoresis process. The sample contained $1 \mathrm{ml}$ plasmids pBT7-N-His-F, $2 \mathrm{ml}$ loading dye 2 , and $3 \mathrm{ml} \mathrm{H}_{2} \mathrm{O}$. Samples were loaded into agarose gel well for the electrophoresis process. The other well loaded with DNA ladder $100 \mathrm{bp}$ as a marker of DNA size. The electrophoresis process was set for 45 minutes in 80 voltage electricity. The results of electrophoresis were visualized by UV Transilluminator resulted in glowing bands.

Restriction Digestion of Recombinant Plasmid with Eco R1 Enzyme. As a sample, plasmid pBT7-N-His-F was digested using the EcoR1 enzyme to separate vectors and inserts. The mixture used for digesting consisted of $4 \mathrm{ml}$ plasmid pBT7-N-His-F, $2 \mathrm{ml}$ EcoR1 enzyme, $2 \mathrm{ml}$ enzyme buffer, and $12 \mathrm{ml} \mathrm{H}_{2} \mathrm{O}$. The mixture was put inside the Eppendorf tube and homogenized with a vortex mixer. The 
samples were then incubated at a temperature of $37^{\circ} \mathrm{C}$ for 4 hours. Next, the digestion results were visualized by DNA electrophoresis with a $1 \%$ agarose gel. Samples used included whole pBT7N-HisF plasmid and digested pBT7-N-His-F plasmids. The whole plasmid formulation was $2 \mathrm{ml}$ plasmids pBT7-N-His-F, $2.5 \mathrm{ml}$ loading dye, and $5 \mathrm{ml} \mathrm{H}_{2} \mathrm{O}$ while digested plasmid formulation was $2 \mathrm{ml}$ digested plasmids pBT7-N-His-F, $2.5 \mathrm{ml}$ loading dye, and $5 \mathrm{ml}$ of $\mathrm{H}_{2} \mathrm{O}$. The electrophoresis process lasted for 1 hour with an 80 voltage of electricity. The electrophoresis results were observed by UV Transilluminator resulted in the glowing bands of DNA with particular molecular weight.

Protein Expression with AccuRapid ${ }^{\mathrm{TM}}$ Cell-free Protein Expression Kit. Recombinant protein expressions on plasmids samples of pBT7-N-His-F were using AccuRapid ${ }^{\mathrm{TM}}$ Cell-free Protein Expression Kit (Bioneer, South Korea). The pBT7-N-His-F plasmids sample of the C-1b clone had been confirmed to have the NDV F protein gene encoder insertion. AccuRapid ${ }^{\mathrm{TM}}$ Cell-Free Protein Expression Kit has several components for the process of protein expression i.e. master mix, E. coli extract, template DNA, and DEPC-DW. The pBT7-N-His-F plasmids samples were mixed with other ingredients with the corresponding composition as listed in Table 1. Besides the samples, positive and negative control were also prepared for comparison in the results of the study.

\begin{tabular}{cccc}
\hline Components & Negative control & Positive control & Sample \\
\hline Master mix & $21 \mu \mathrm{L}$ & $21 \mu \mathrm{L}$ & $21 \mu \mathrm{L}$ \\
Ekstrak E. coli & $12 \mu \mathrm{L}$ & $12 \mu \mathrm{L}$ & $12 \mu \mathrm{L}$ \\
DNA template & - & $1 \mu \mathrm{L}$ & $6 \mu \mathrm{L}$ \\
DEPC- DW & $12 \mu \mathrm{L}$ & $11 \mu \mathrm{L}$ & $6 \mu \mathrm{L}$ \\
Total & $45 \mu \mathrm{L}$ & $45 \mu \mathrm{L}$ & $45 \mu \mathrm{L}$ \\
\hline
\end{tabular}
Kit

All components for the expression process are loaded into the Eppendorf tubes respectively i.e. samples, negative controls, and positive control and mixed with vortex mixers until homogeneous. The mixture of components is incubated for 3 hours in $30^{\circ} \mathrm{C}$. The incubation results to be concentrated at the base of the tubes using spin-down.

SDS-PAGE. The results of the expression pBT7-N-His-F plasmids using the AccuRapid ${ }^{\mathrm{TM}}$ Cell- $^{-}$ free Protein Expression Kit were visualized with Sodium Dodecyl Sulphate-Polyacrylamide Gel Electrophoresis (SDS-PAGE). The polyacrylamide gel concentration on separating gel was $12 \%$ made by mixing $10 \mathrm{ml}$ of separating gel 12\%, $10 \mathrm{ml}$ TEMED, and $100 \mathrm{ml}$ APS $10 \%$. After homogeneous, the mixture was then poured into the gel mold and added with butanol on the top of the layer so that there were no air bubbles and flat gels. When the gel was packed, it was added with a 5\% stacking gel on the top of the gel. Stacking gel was made by mixing $5 \mathrm{ml}$ stacking gel $5 \%$ with $5 \mathrm{ml}$ TEMED and $50 \mathrm{ml}$ APS $10 \%$ which then poured onto the gel mold. Once the gel was compacted, the polyacrylamide gel was inserted into the electrophoresis tank and soaked in protein electrophoresis buffer of Tris- $\mathrm{HCl}$, glycine, and SDS $10 \%$.

Samples used consisted of recombinant $\mathrm{F}$ protein as much as $5 \mathrm{ml}$ added with $10 \mathrm{ml} \mathrm{H}_{2} \mathrm{O}$ and $5 \mathrm{ml}$ loading dye in the Eppendorf tube then homogenized by a vortex mixer. The samples were then heated into boiling water for 3 minutes and then cooled into the ice water for 10 minutes. The sample was then loaded into the polyacrylamide gel as much as $5 \mathrm{ml}$. The electrophoresis process was performed for 2 hours in $100 \mathrm{~V}$ electricity. The results of the SDS-PAGE were stained with $0.1 \%$ Coomassie brilliant blue for 3 hours, placed above the shaker to be perfectly colored. After staining, de-staining using a destaining solution consisted of glacial acetic acid, methanol, and $\mathrm{H}_{2} \mathrm{O}$ was done 3 times. The results of the SDS-PAGE were categorized by protein bands that were colored by the position of the corresponding molecular weight of each protein.

Western Blot. The SDS-PAGE gel was placed in the transfer buffer to move proteins from the polyacrylamide gel to the PVDF membrane. The paper was two pieces each of thick and thin Whatman 
paper and PVDF membrane cut according to the size of the gel. Whatman paper was soaked in the transferring buffer before use. The order of arrangement of western blot used from anode to the cathode was as follows thick Whatman paper, thin Whatman paper, PVDF membrane, SDS-PAGE gel, thin Whatman paper, and thick Whatman paper. Western blot tools were closed then the blotting process started for 1 hour in $500 \mathrm{~mA}$ voltage of electricity.

After the blotting process, the PVDF membrane was then soaked in a $1 \%$ BSA blocking solution in $0.5 \%$ tween for 1 hour at room temperature using a shaker. The blocking result was washed with $0.05 \%$ TBS tween 3 times with 5 minutes each. The 6x mouse epitope tag antibody (Invitrogen, Canada) was added as much as $5 \mathrm{ml}$ as a primary antibody and then diluted with a comparison of 5\% BSA and $0.1 \%$ TBS-Tween $=1: 2000$ and incubated one night in a temperature of $4^{\circ} \mathrm{C}$. After the incubation process, the PVDF membrane was washed with $0.05 \%$ TBS-Tween 2 times with 5 minutes each and 1 time for 10 minutes. Washing results which added with conjugated goat anti-mouse IgG Affinity Purify (Thermo Fisher Scientific, USA) with a comparison of $1: 15,000$ as a secondary antibody with $1 \%$ BSA in $0.05 \%$ TBS-Tween were then incubated for 1 hour in room temperature using a shaker. After the incubation process was completed, the PVDF membrane was washed with TBS-Tween $0.05 \% 2$ times in 5 minutes each and 2 times in 10 minutes each. The washing result was added with a substrate of 1-StepTM NBT/BCIP (Thermo Fisher Scientific, USA) until the visible ribbon appeared with a specific position depending on the protein size. The results of these ribbons show the weight of each specific protein.

\section{Results and Discussion}

Before expression, samples of plasmid colonies $\mathrm{C}-1 \mathrm{~b}$ needed to be examined and verified to indicate that the C-1b colony contained plasmid pBT7-N-His-F. Plasmid pBT7-N-His which has an F proteinencoding gene insertion weighted 4,643 bp. The verification method was performed by electrophoresis using a 1\% agarose gel indicated by its DNA bands in the agarose gel (Figure 1).

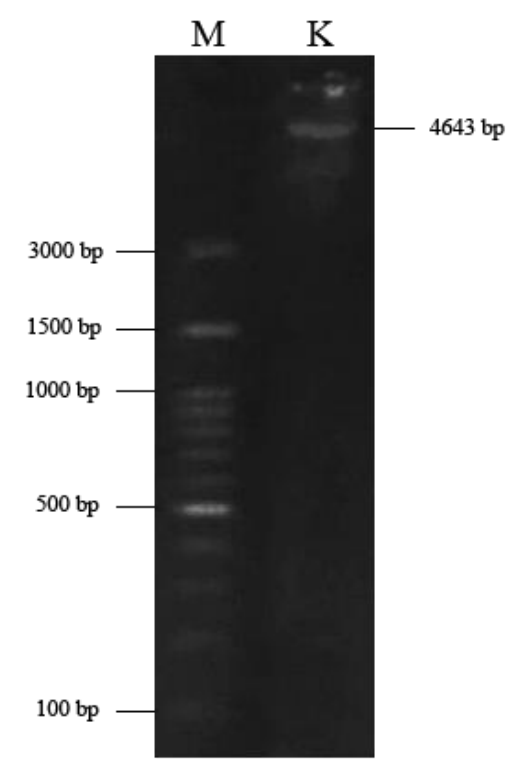

Figure 1: Electrophoresis result of pBT7-

$\mathrm{N}-\mathrm{His}-\mathrm{F}$ plasmids recombinant on an agarose $1 \%$ gel. $\mathrm{M}=$ DNA marker ladder 
$100 \mathrm{bp}, \mathrm{K}=$ Plasmid recombinant pBT7-

N-His-F Colony C-1b.

As seen in column $\mathrm{K}$, the DNA band of recombinant plasmid pBT7-N-His-F with a weight of 4,643 bp indicated that the colony $\mathrm{C}-1 \mathrm{~b}$ had a pBT7-N-His-F plasmid. The three bands were confirming that the plasmids had three conformations, namely supercoiled, nicked circle, and linear segments. The bottom band is a plasmid with a conformation of supercoiled, the middle band is a plasmid with a nicked circle conformation, and the top band is a plasmid with a linear conformation. The three plasmid bands conformation has the same weight yet is affected by the migration speed of the plasmids in the gel (Dale et al., 2004).

After confirming that the $\mathrm{C}-1 \mathrm{~b}$ colony had plasmids pBT7-N-His-F, the verification method for a recombinant $\mathrm{F}$ protein-encoding gene in the pBT7-N-His vector is done by digesting the plasmids using an EcoR1 restriction enzyme. The EcoR1 enzyme will cut the phosphodiester bond in the plasmids' DNA at the nitrogen base order of G/AATTC with the complement of the CTTAA/G (Kurpiewski et al., 2004). These cuts would separate the recombinant F-encoding gene inserts with the pBT7-N-His vector. Vector pBT7-N-His weighted 4,001 bp whereas the F recombinant proteins gene inserts weighted $642 \mathrm{bp}$. To find out the result of the digesting process, the F protein-encoding gene inserts were separated from the vector pBT7-N-His by electrophoresis in the 1\% agarose gel (Figure 2).

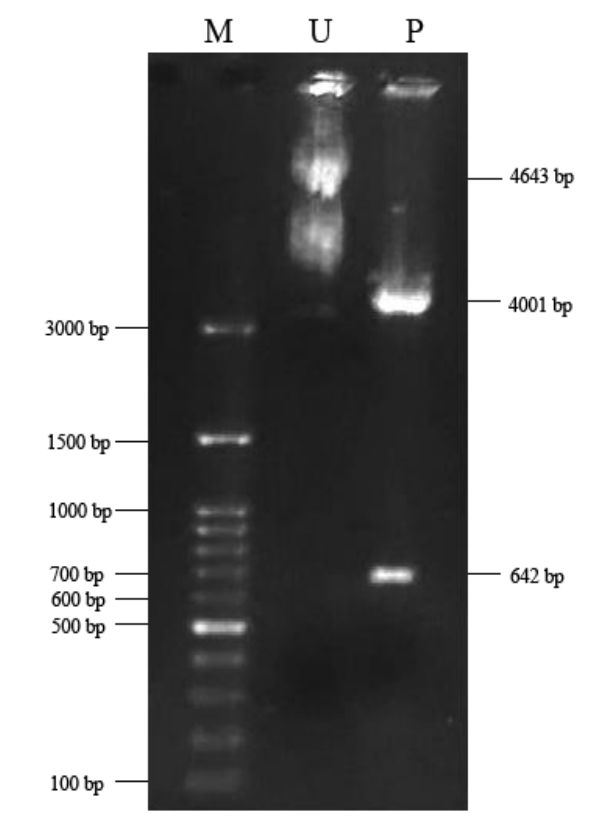

Figure 2: Electrophoresis results of digested pBT7-N-his-F plasmids with EcoR1 enzyme on the agarose $1 \%$ gel. $\mathrm{M}=\mathrm{DNA}$ marker ladder $100 \mathrm{bp}, \mathrm{U}=$ Whole $\mathrm{pBT} 7-\mathrm{N}-\mathrm{His}-\mathrm{F}$ plasmids, $\mathrm{P}=$

Digested pBT7-N-His-F plasmid with EcoR1 enzyme.

As seen in column $\mathrm{P}$, there are two bands with a weight of 4,001 bp and $642 \mathrm{bp}$. According to the Bioneer, vector pBT7-N-His has a size of 4,001 bp so that there was an insertion of the F gene-encoding recombinant protein with a weight of $642 \mathrm{bp}$. According to Wulanjati et al. (2018), the length of the total F protein gene of ND virus from the isolates of Kulon Progo (0663/04/2013) is 1,681 BP, with a cleavage site at the amino acid number 112-117. In the inserted F protein gene, there is a partial proteinencoding gene that has been cut and has a cleavage site with a weight of $642 \mathrm{bp}$. The presence of these two bands showed that the digesting process of pBT7-N-His-F with the EcoR1 enzyme separates the 
plasmids vectors with the gene insert. Column U shows a comparison for whole plasmids pBT7-N-HisF with a weight of 4,643 bp. This result indicated that the plasmids pBT7-N-His-F Colony C-1b had the recombinant $\mathrm{F}$ protein-encoding gene inserts for the next step in the recombinant protein $\mathrm{F}$ expression from ND virus.

After confirming that the plasmid pBT7-N-His-F had a recombinant protein F-encoding insertion gene on the $\mathrm{C}-1 \mathrm{~b}$ colony, the recombinant protein $\mathrm{F}$ expression from ND virus were carried out using in vitro methods using the AccuRapid ${ }^{\mathrm{TM}}$ Protein Expression Kit from Bioneer. The kit contained E. coli extract so that the process of protein expression would run in vitro. According to Zemella et al. (2015), the Cell-free expression method is a simple and fast way with high protein results, and the use of Genetic modification techniques is easier. This expression process was done for 3 hours with an incubation temperature of $30^{\circ} \mathrm{C}$. During this expression process, there was transcription and translation to form the recombinant $\mathrm{F}$ protein of the ND virus. The protein expression results were visualized by electrophoresis in SDS-PAGE $12 \%$ with $100 \mathrm{~V}$ electricity. The electrophoresis ran for 1 hour and 30 minutes and stained with Coomassie Brilliant Blue (CBB) to color the protein band (Figure 3). Compared to the marker ladder (column M), the recombinant F protein weighted $25.6 \mathrm{kDa}$ (column K). The formation of a recombinant $\mathrm{F}$ protein indicated that the protein expression was succeeded. As a comparison, in the research using the F-protein full-length ND virus with a molecular weight of $55 \mathrm{kDa}$ the results of recombinant protein expression as evidenced by the technique of SDS-PAGE with polyacrylamide gel 12\% (Siddappa et al., 2014).

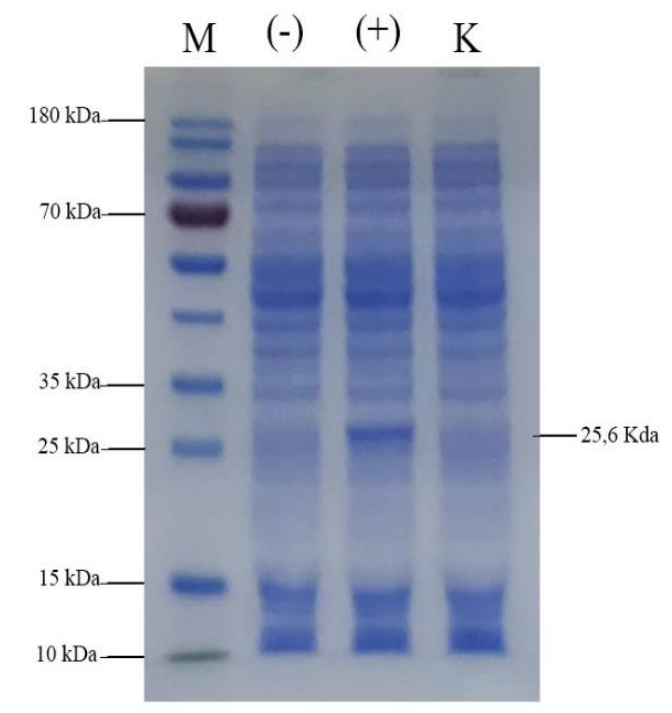

Figure 3: Protein expression results of $\mathrm{F}$ recombinant protein visualized in SDS-PAGE $12 \%$. M = Protein marker ladder 10-180 kDa, $(-)=$ Negative control, $(+)=$ positive control, $\mathrm{K}=$ Recombinant $\mathrm{F}$ Protein of plasmids pBT7-N-His-F Colony C-1b.

The results of the electrophoresis of the proteins still showed the presence of bands from other proteins so that more specific visualizations were performed using the Western blot technique. The Western Blot technique utilizes the existence of $6 x$ histag which is in the gene insertion of the recombinant protein F-encoding so that the antibodies are given $6 x$ histag. The $6 x$ histag attaches to the C-terminus of the nucleocapsid protein monomer so that it will be specifically recognized by the antibody of 6x histag. In principle, the Western blot method is the transfer of the results of protein from electrophoresis to the polyvinyl difluoride (PVDF) membrane with the electric flow and some filter 
paper such as Whatman paper. The protein bands that have been moved to the Nitrocellulose membrane will be detected using 6x histag antibodies that will undergo a complex binding reaction of antigenantibodies so that it can be identified with the addition of 1-StepTM NBT/BCIP substrate (Nitro-Blue Tetrazolium chloride and 5-Bromo-4chloro 3' indolyphospate P-toluidine salt) (Thermo Fisher Scientific) so it can be colored at a specific part that has the antibodies histag. The primary antibody used in this research was a 6x mouse epitop tag antibody tags while the secondary antibodies used were Goat Anti-Mouse IgG. The Western blot results are shown in Figure 4.

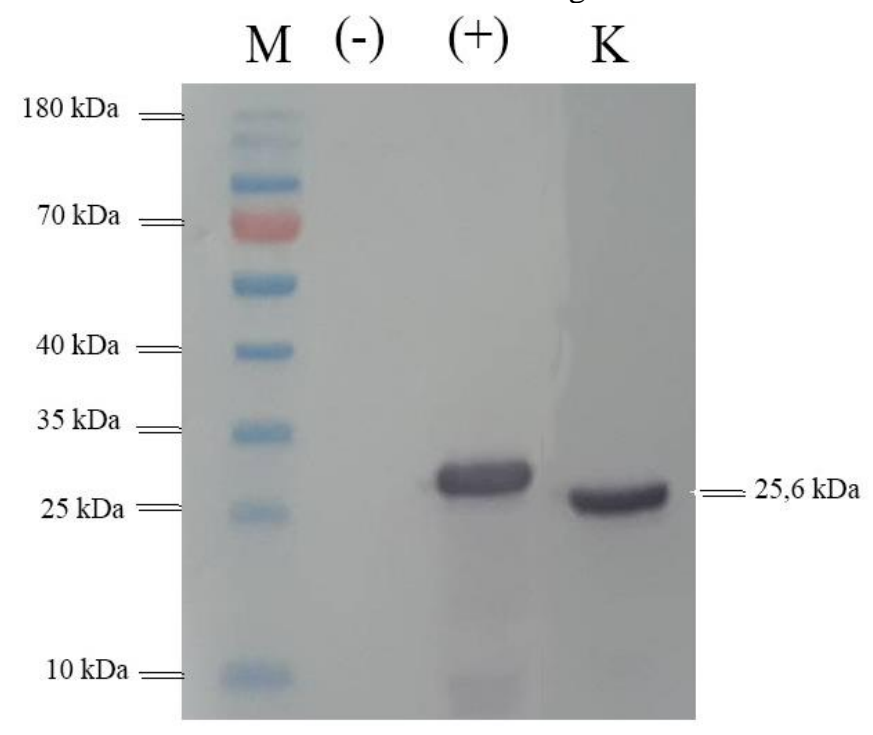

Figure 4: Western blot result of $F$ recombinant protein ND virus. $\mathrm{M}=$ Protein marker ladder 10-180 kDa, (-) = Negative control, (+) = positive control, $\mathrm{K}=$ Recombinant $\mathrm{F}$ Protein of plasmids pBT7N-His-F Colony C-1b.

As seen in column $\mathrm{K}$, the Western blot method resulted in one protein band with a molecular weight of $25.6 \mathrm{kDa}$. This indicated that the expression of protein F recombinant ND virus using AccuRapid ${ }^{\mathrm{TM}}$ Protein expression kit was succeeded. In another study by Astuti et al. (2018), the results of protein expression utilizing a broiler hen vaccine were also capable of forming the anti-protein $\mathrm{F}$ antibody of ND virus with satisfactory results. In this case, the use of recombinant F protein when injected into the animal can induce the animal immune system by forming IgG and F-specific cellular immunity (Kang et al. (2016). Therefore, recombinant F proteins become one of the vaccine subunit candidates for ND virus. This study also showed that the use of in vitro free-cell protein expression system gave good results, as well as fast and simple. The successful expression of ND virus F protein from the C-1b clone of E. coli was an alternative to C-1a E. coli clone as conducted by Putri and Haryanto (2019). Additionally, this method can also be used for other protein expressions. Moreover, the recombinant $\mathrm{F}$ protein of ND virus from local isolates are potential to be the initial ingredient for the ND vaccine as one way to prevent and countermeasures the ND virus infection in the field.

\section{Acknowledgment}


The authors would like to give great appreciation to the authorities of the Faculty of Veterinary Medicine and Universitas Gadjah Mada for providing facilities and support to this research. This work was supported by the research grant of Recognisi Tugas Akhir (RTA) from Universitas Gadjah Mada Yogyakarta, the fiscal year 2019 with Grant No. 3114/UN1/DITLIT/DIT-LIT/LT/2019 on April 11 ${ }^{\text {th }}$, 2019.

\section{References}

Astuti RW. (2018). Ekspresi Protein Fusion (F) Rekombinan Virus Newcastle Disease Isolat Lokal dan Studi Produksi Antibodi Anti Protein F Rekombinan pada Ayam Broiler Pasca Vaksinasi. PhD thesis. In Bahasa. Universitas Gadjah Mada.

Czegeldi A, Ujvari D, Somogyi E, Wehmann E, Werner O, and Lomniczi B. (2006). Third genome size category of avian paramyxovirus serotype 1 (Newcastle disease virus) and evolutionary implications. Virus Research. 120: 36-48.

Dale JW, Dale PJW, and Park SF. (2004). Molecular Genetics of Bacteria Fourth Edition. UK: Wiley.

Kang X, Wang J, Tang P, Song L, Xiong D, and Jiao X. (2016). Expression of recombinant Newcastle disease virus $F$ protein in pichia pastoris and its immunogenicity using flagelin as the adjuvant. Protein Expression and Purification. 128: 73-80.

Kurpiewski MR, Engler LE, Wozniak LA, Kobylanska A, Koziolkiewicz M, Stec WJ, and JenJacobson L. (2004). Mechanisms of coupling between DNA recognition specificity and catalysis in EcoRI endonuclease. Structure. 12(10): 1775-88.

Lee DH, Kwon JH, Noh JY, Park JK, Yuk SS, Ochir TOE, Nahm SS, Kwon YK, Lee SW, and Seon C. (2016). Viscerotropic velogenic Newcastle disease virus replication in feathers of infected chickens. $J$ Vet Sci. 17(1): 115-117.

Nascimento IP, and Leite LCC. (2012). Recombinant vaccines and the development of new vaccine strategies. J Med Biol Res. 45(12): 1102-1111.

Putri CN and Haryanto A. 2019. Fusion recombinant protein expression of Newcastle disease virus from E. coli clone of C-1a using Accurapid ${ }^{\mathrm{TM}}$ protein expression kit. IOP Conference Series: Earth Environ. Sci. 355 (1): 012026.

Quinn PJ, Markey BK, Leonard FC, FitzPatrick ES, Fanning S, and Hartigan PJ. (2011). Veterinary Microbiology and Microbial Disease.Second Edition. UK: Wiley-Blackwell.

Rehmani SF, Wajid A, Bibi T, Nazir B, Mukhtar N, Hussain A, Lone NA, Yaqub T, Afonso CL, and Tang YW. (2015). Presence of Virulent Newcastle Disease Virus in Vaccinated Chickens in Farms in Pakistan. JCM. 53(5): 1715-8.

Sidappa M, Vijayarani K, and Kathaperumal K. (2014). Expression of full-length fusion (F) protein gene of Newcastle disease virus in mammalian expression system Article in The Indian journal of animal sciences. 84(4): 364-367.

Wulanjati MP, Wijayanti N, and Haryanto A. (2018). Phylogenetic Analysis of Newcastle Disease Virus from Indonesian Isolates Based on DNA-Sequence of Fusion Protein-Encoding Gene. Biotechnology. 17: 69-74.

Yamamoto E, Ito T, Ito1 H. (2016). Completion of full-length genome sequence of novel avian paramyxovirus strain APMV/Shimane67 isolated from migratory wild geese in Japan. J Vet Med Sci. 78(10): 1583-1594.

Zemella A, Thoring L, Hoffmeister C, and Kubick S. (2015). Cell-Free Protein Synthesis: Pros and Cons of Prokaryotic and Eukaryotic Systems. Chembiochem. 16(17): 2420-2431. 